\title{
Mapping New Zealand 2025 - A National Perspective
}

\author{
Karl Baker ${ }^{\mathrm{a},} *$, Roger Carman ${ }^{\mathrm{b}}$, Graeme Blick $^{\mathrm{c}}$, Stuart Caie ${ }^{\mathrm{d}}$ \\ ${ }^{a}$ Land Information New Zealand (LINZ),New Zealand, kbaker@linz.govt.nz \\ ${ }^{b}$ Land Information New Zealand (LINZ),New Zealand, rcarman@linz.govt.nz \\ ${ }^{c}$ Land Information New Zealand (LINZ),New Zealand, gblick@linz.govt.nz \\ ${ }^{d}$ Land Information New Zealand (LINZ),New Zealand, scaie@linz.govt.nz \\ * Corresponding author
}

Keywords: Mapping, topography, bathymetry, LiDAR, coastal mapping, national mapping

\begin{abstract}
:
Land Information New Zealand (LINZ) is in a unique position internationally. This Central Government organisation houses New Zealand's national mapping agency, hydrographic authority and geodetic survey office all under one roof. This gives the organisation the opportunity to think broadly about future directions and leverage a combined centre of expertise and skills, across the three disciplines, nationwide.
\end{abstract}

In 2007, LINZ launched the Geospatial Strategy to improve coordination, sharing and use of geospatial data across New Zealand's government entities. The Strategy had four goals - good governance across the system; creating and maintaining key geospatial datasets; accessible and useable Government geospatial data; and interoperability.

Since then, LINZ has begun a 10-year programme of work - Mapping New Zealand 2025 - to deliver the mapping, data and expertise needed to address some of the most significant challenges facing the country, now and in the future firstly resilience and climate change, secondly urban growth and thirdly water. These three challenges prioritise LINZ's work under its 2017 Outcomes Framework. The vision is seamless land and sea mapping, from the top of Aoraki/Mount Cook to the edge of the continental shelf.

Mapping New Zealand 2025 brings together initiatives, leadership and investment, and builds on core LINZ expertise in mapping and charting, data partnerships with other organisations and new technologies to deliver this programme.

This paper will give an outline and update on the five major components that make up the Mapping New Zealand 2025 work programme.

1. Improving New Zealand's Bathymetry Data - Decision-makers around the world are increasing their use of marine information to tackle issues such as the sustainability of ocean resources. LINZ is working with national and international organisations on projects to drive improvements in New Zealand's depths information and to map the world's ocean floors. Coupled with international projects, LINZ is also focusing on local initiatives such as building relationships and partnerships to ensure valuable New Zealand marine data is collected efficiently, is more accessible and reusable. The organisation is also now coordinating retrieval of data, samples and reports from international vessels undertaking marine science research in New Zealand's Exclusive Economic Zone, Territorial Sea and Continental Shelf.

2. National Elevation and Imagery Partnerships - Aerial imagery and elevation (LiDAR) are foundational data infrastructure for New Zealand, with many critical applications. LINZ operates a successful partnership model for procuring and publishing aerial imagery across New Zealand, an initiative begun after the Canterbury earthquakes, when imagery over Christchurch was in great demand, but not accessible. The initiative has made aerial imagery of the entire country available to all, under a creative commons licence. LINZ has also recently established national coordination of elevation (LiDAR) data to maximise its value to New Zealand. Coordinating procurement partnerships and publishing data for open reuse are the focus of this ambitious initiative.

3. Mapping the coastal zone - New Zealand's coastal zone is of great economic, social and environmental importance, and it is where climate change processes will impact the most. Fit-for-purpose coastal mapping is essential to modelling and decision-making that help us adapt and mitigate risks to our communities, individual property and infrastructure. LINZ is undertaking a one-year pilot as an initial step towards determining the needs for, and benefits of, improved coastal mapping. The pilot is stocktaking existing datasets that map parts of the coast (or intertidal or littoral zone) and identifying a fit-for-purpose reference frame for analysing data. The work will then move on to investigate the products needed to improve coastal mapping and decision-making and develop a prototype tool for mapping and visualisation. 
4. Joining land and sea data - Currently in New Zealand, elevation and depths datasets are captured to a range of reference surfaces and datums, limiting our ability to merge them together. The largest challenges are across the coastal zone, where LINZ is working with the National Institute of Water \& Atmospheric Research (NIWA) to develop a tool for 'seamless' linking of land and sea data. This project is being run in tandem with improving coastal mapping mentioned above, as the definition of tidal surfaces (such as mean high-water springs) are limited by the accuracy of digital terrain models and the ability to connect tidal surfaces to the coast. This project will also deliver an improved national tidal model. New Zealand's current model was developed between 1996 and 2000 and is built on a now obsolete platform. The updated model will be recreated on a new platform and be able to use 20 additional years of data and improvements in global modelling technologies.

5. Maximising the benefits of Earth observation data - 2018 saw a greatly increased awareness of the potential applications of Earth observation data and technologies in government, industries and research in New Zealand. LINZ is joining with major stakeholders such as the Ministry of Business, Innovation and Employment's Space Agency, Venture Southland and the Centre for Space Science Technology to develop a national strategy for maximising the benefits of Earth observation. Aside from this national focus, LINZ will work on how best to utilise Earth observation in our own activities, in areas such as using remote sensing to map our built environments and understanding potential applications for interferometric synthetic aperture radar (InSAR), which uses radar images of Earth's surface collected by satellites to map ground deformation.

Each of these five projects are at different stages of maturity. The presentation will cover off what each project has accomplished to date. We will present what the future holds for the programme and how Mapping New Zealand 2025 will allow LINZ, and the wider New Zealand community, to think and work differently. 